\title{
Spatiotemporal Characteristics and Influencing Factors of China's Construction Industry Carbon Intensity
}

\author{
Qiang Du ${ }^{1}$, Min Wu ${ }^{2}$, Ning Wang ${ }^{2}$, Libiao Bai ${ }^{1 *}$ \\ ${ }^{1}$ School of Economics and Management, Chang'an University, Middle Section of South Second Ring Road, \\ Xi' an 710064, China \\ ${ }^{2}$ School of Civil Engineering, Chang' an University, \\ 161 Middle Chang'an Road, Xi’an 710061, China
}

Received: 11 February 2017

Accepted: 3 May 2017

\begin{abstract}
Climate change continuously threatens sustainable development. As the largest energy consumer and carbon emitter in the world, China is facing increasing pressure to cut carbon emissions. Based on Moran's index I and geographically weighted regression, this paper investigates the spatiotemporal characteristics and the dominating factors of China's province-level carbon intensity in the construction industry from 2005 to 2014, which is aimed at providing a scientific basis for government while implementing a regionaloriented carbon emissions reduction strategy. The empirical results are shown as follows. Firstly, carbon intensity in the construction industry of each province has been decreasing in the past 10 years. Secondly, provincial carbon intensity in this sector shows significant positive spatial autocorrelation characteristics and the degree of spatial clustering of carbon intensity tended to weaken in this period. Third, according to the analysis of the geographically weighted regression (GWR) model, carbon intensity is positively affected by energy intensity while the labor input and production efficiency both have negative effect. Particularly the regression coefficient of labor input is almost twice as large as the other two factors. The results reveal that there is a significant spatial disparity of these three factors in different provinces.
\end{abstract}

Keywords: construction industry, carbon intensity, spatial autocorrelation, Moran's I, geographically weighted regression

\section{Introduction}

Climate change continuously threatens human and ecological environments. As the extravagant greenhouse gas (GHG) emissions are not conducive to preserve

*e-mail: hanshannuanyang@chd.edu.cn the Earth's climate and temperature, many national and international entities have made commitments to minimize the carbon footprint [1]. As the largest energy consumer and carbon emitter in the world, China is facing increasing pressure on cutting its $\mathrm{CO}_{2}$ emissions down [2-3]. In this context, the Chinese government released a mitigation action plan to reduce carbon emission intensity by 40 to $45 \%$ in 2020 based on 2005 levels [4]. Because of the massive utilization of materials 
and equipment, the construction industry produces a large amount of greenhouse gases. For example, the construction industry in the United States ranks third for its carbon dioxide emissions per unit of energy used as input [5-6]. Cement and steel production industries rank first and second [7], which supply construction projects with necessary materials. In order to deal with the increasingly severe challenge of environmental deterioration in China, it is required to take the issue of $\mathrm{CO}_{2}$ emissions into account in the construction industry [8]. Control of $\mathrm{CO}_{2}$ emissions in this sector contributes immeasurably to formulate practical carbon emissions reduction and environmental protection policies. There is obvious regional disparity among the carbon emissions and economic development due to China's immense territory. All provinces have a close relationship with each other [9]. It's essential to take spatial dependence into consideration in policy making. The spatial dependence implies that carbon-reduction policies implemented in one province may have spillover effects in neighboring provinces [10]. Thus in the context of the development of both urbanization and industrialization, it is necessary for energy and environmental politicians of China to investigate the spatiotemporal characteristics and the influence factors of China's $\mathrm{CO}_{2}$ emissions in the construction industry in order to craft more effective policies.

The issue of climate change has attracted more and more attention from researchers in the most recent decade. An increasing number of scholars has started to research methods to curb increasing carbon emissions, particularly by exploring the factors that influence $\mathrm{CO}_{2}$ emissions, which has become a popular topic.

Past studies have focused mainly on exploring the main factors driving carbon emissions of China with various methods. Based on the Path-STIRPAT (stochastic impacts by regression on population, affluence, and technology) model, a method combining Path analysis with STIRPAT, Li et al. [11] found that the main factors influencing China's $\mathrm{CO}_{2}$ emissions were GDP per capita, industrial structure, population, urbanization level, and technology level. Under decomposition analysis using the log mean divisia index (LMDI) method, Xu et al. [12] and Zhang and $\mathrm{Da}$ [13] found that the economic output effect appeared to be the main factor that influences carbon emissions and other factors with intense energy and energy structure effects. Based on the Laspeyres Decomposition Method, Lu et al. [14] analyzed the characteristics of China's carbon productivity change and the sources of industry structure from 2003 to 2011. They found that the structural factors had an inhibitory effect on China's carbon productivity, and carbon productivity growth came mainly came from industry production efficiency. At the same time, some scholars analyzed driving factors from the point of a region, which respectively took Liaoning, Tianjin, Taiwan, and Guangdong as examples [15-18]. As for the construction sector, Lu et al. [19] calculated China's construction carbon emissions over 1994-2012 by identifying the impact of the main driving factors based on LMDI. They found that energy intensity had a major inhibitory effect on carbon emissions, followed by machinery efficiency. Using the LMDI method, Feng and Wang [20] discussed the influence factors of carbon emissions in China's construction industry from 2004 to 2011. Results showed that energy carbon emission intensity effect, energy structure effect, and energy intensity effect had a negative impact on carbon emissions, while the indirect carbon intensity effect and industry scale effect had a positive impact. Moreover, other scholars have uncovered the main influencing factors of carbon emissions from the perspective of other sectors in China, such as the manufacturing industry, mining sector, and electric power sector [21-23].

A possible shortcoming of these studies is to assume that regions are independent and the significant spatial interaction effects are ignored. Anselin [24] and LeSage and Pace [25] pointed out that the characteristics of a local region may depend on neighboring regions. The assumption that the variables are independent is broken and that ignoring spatial autocorrelation would lead to model misspecification or estimation bias.

Recognizing the importance of spatial effects, Burnett et al. [26] studied the relationship between U.S. statelevel carbon dioxide $\left(\mathrm{CO}_{2}\right)$ emissions, economic activity and other factors with several spatial panel data models. They suggested that economic distance between states had a positive and statistically significant effect on their own and neighboring $\mathrm{CO}_{2}$ emissions, and there were statistically significant, positive economic spillovers and negative price spillovers to state-level emissions. Using panel data of China's 30 provinces from 1999 to 2011, Yang et al. [27] analyzed the effects of different technological factors on industrial $\mathrm{CO}_{2}$ intensity, including indigenous research and development (R\&D) activity, spillovers through increasing openness, and interregional R\&D spillovers. Based on novel spatial panel data models, Zhao et al. [28] analyzed the drivers of energy-related emission intensity of 30 provinces in China covering the period 1991-2010. They found that carbon dioxide emission intensity in China tends to cluster together and per-capita, province-level GDP and population density exerted a negative effect on emission intensities, whereas emission intensities were positively affected by the energy consumption structure and the transportation sector. However, energy prices had no effect on emission intensities. Cheng et al. [29] examined the spatiotemporal dynamics and driving factors of carbon intensity from energy consumption in China over 1997-2010 based on the spatial autocorrelation analysis and spatial panel econometric model. They suggested that carbon intensity had a growing spatial agglomeration at the provincial scale and energy structure, energy intensity, urbanization rate, and industrial structure were the main factors that shaped the spatiotemporal dynamic patterns of carbon intensity from energy consumption in China. Using Moran's I 
and spatial panel data models, Long et al. [10] found that there was significant positive spatial dependence and clustering characteristics in China's provincelevel industrial carbon productivity. They suggested that the positive factors of carbon intensity were industrial energy efficiency, the opening degree, technological progress, and the industrial scale structure, whereas carbon intensity was negatively affected by per-capita GDP, industrial energy consumption structure, and the industrial ownership structure. These studies have shown that the regional disparity and spatial dependence of carbon emissions cannot be neglected.

However, very few studies have been reported on the spatial dependence of China's carbon emissions, particularly in the construction industry. This paper tends to explore the driving factors of carbon intensity in this sector from the perspective of spatial effect. To identify spatial dependence, it is essential to examine the spatial distribution of carbon intensity by provincial data from 2005 to 2014. Furthermore, this paper analyzes the spatial autocorrelation by Moran's I and local Moran's I before examining the dominating factors based on the method of geographically weighted regression. It is expected that such research can provide a scientific basis for the government while implementing a regional oriented carbon-reduction strategy for the construction industry.

This study offers three contributions to existing literature:

Measuring China' carbon intensity in the construction industry using a more accurate method. Two different methods were used to calculate carbon emissions from primary energy and secondary energy, respectively.

It extends the data to examine 30 provinces in China from 2005 to 2014, which could well capture recent characteristics of carbon intensity in the construction industry and developments in provincial economic growth.

This study uses developed spatial econometric models to further explore the spatial autocorrelation and the driving forces of carbon intensity in the construction sector.

\section{Methods}

Data

\section{Formulation of Carbon Intensity}

This study uses carbon intensity in the construction industry as the dependent variable, which includes panel data of China's 30 provinces and municipalities from 2005 to 2014 (Hong Kong, Macao, Taiwan, and Tibet are not included due to lack of data). Carbon intensity in the construction industry can be defined as Eq. (1):

$$
C I=\frac{C_{T}}{C I O V}
$$

...where $C I$ represents carbon intensity in construction industry, $\mathrm{CIOV}$ refers to the construction industry output values, and $C_{T}$ stands for the total carbon dioxide emissions in the construction sector. The provincial construction industry output values are obtained from the provincial statistical yearbooks.

The types of construction industry energy consumption in China include primary energy such as coal, coke, crude oil, gasoline, kerosene, diesel oil, liquefied petroleum gas and natural gas, and secondary energy such as heat and electricity. The calculation process of the direct carbon dioxide emissions from primary energy in the construction industry is conducted as follows:

$$
C_{D_{1}}=\sum_{i=1} E_{i} \times N C V_{i} \times A_{i} \times O_{i} \times 44 / 12
$$

$\ldots$ where $C_{D_{1}}$ denotes the direct $\mathrm{CO}_{2}$ emissions from primary energy in the construction industry, $i$ is the type of energy, $E_{i}$ represents the consumption of energy $i$ (which can be obtained from the provincial statistical yearbooks), $N C V_{i}$ represents the average lower-order calorific value of energy $i$ provided by the China Energy Statistical Yearbook, $A_{i}$ is the carbon content per unit heat of energy $i$, $O_{i}$ represents the oxidation rate of energy $i$, and the figure $44 / 12$ is the molecular weight ratio of $\mathrm{CO}_{2}$ to carbon. The carbon content per unit heat and the oxidation rate of each fuel type can be derived from the Guidelines to Make Provincial Lists of Greenhouse Gas Inventory. The direct carbon dioxide emissions from secondary energy such as heat and electricity are calculated with the following equation.

$$
C_{D_{2}}=\sum_{i=1} E_{i} \times C E F_{i}
$$

...where $C_{D_{2}}$ is the direct $\mathrm{CO}_{2}$ emissions from secondary energy in the construction industry, $E_{i}$ denotes consumption of energy $i$ (which is derived from provincial statistical yearbooks), $C E F_{i}$ represents the $\mathrm{CO}_{2}$ emissions coefficients of energy $i$ obtained from the Guidelines to Make Provincial Lists of Greenhouse Gas Inventory.

Calculating indirect $\mathrm{CO}_{2}$ emissions in the construction industry is usually divided into two steps. First, the paper selects nine industries related to the construction industry, such as mining and washing of coal, extraction of petroleum and natural gas, mining and processing of metal ores, petroleum refining, coking, and nuclear fuel processing, manufacture of raw chemical materials and chemical products, manufacture of non-metallic mineral products, smelting and pressing of metals, manufacture of metal products, and transport, storage, and postal services. The equation of direct $\mathrm{CO}_{2}$ emissions from primary energy of industry $j$ is written as: 


$$
C_{D_{1}, j}=\sum_{i=1} E_{i, j} \times N C V_{i} \times A_{i} \times O_{i} \times 44 / 12
$$

The formula is similar to formula (2). Here $C_{D_{1}, j}$ denotes the direct $\mathrm{CO}_{2}$ emissions from primary energy consumed by industry $j$, and $E_{i j}$ means the use of energy $i$ of industry $j$. The direct $\mathrm{CO}_{2}$ emissions from secondary energy of industry $j$ can be calculated by the following equation:

$$
C_{D_{2}, j}=\sum_{i=1} E_{i, j} \times C E F_{i}
$$

The calculation process is similar to equation (3). Here $C_{D_{2, j}}$ represents the direct $\mathrm{CO}_{2}$ emissions from secondary energy of industry $j$, and $E_{i, j}$ refers to consumption of energy $i$ of industry $j$. Next, based on input-output analysis, the indirect carbon emissions in the construction industry are calculated using the following equation [30]:

$$
C_{I}=\sum_{j} \frac{C_{D_{1}, j}+C_{D_{2}, j}}{I O V_{j}} \times \frac{C I O V}{y_{j}}
$$

...where $C_{D_{1}, j}$ denotes the direct carbon emissions from primary energy of industry $j, C_{D_{2}, j}$ stands for the direct carbon emissions from secondary energy of industry $j, j$ is the category of industries, $I O V_{j}$ refers to the total output values of industry $j$ provided by the provincial statistical yearbooks, CIOV represents the construction industry output values, and $y_{j}$ is the total consumption coefficient of industry $j$ from construction industry (which can be derived from the input-output tables).

Finally, total $\mathrm{CO}_{2}$ emissions in the construction industry are then:

$$
C_{T}=C_{D_{1}}+C_{D_{2}}+C_{I}
$$

\section{Explanatory Variables}

Most of the scholars have investigated the main factors influencing carbon emissions using STIRPAT or LMDI models, whereas others analyzed the factors based on spatial panel data models. The main factors driving carbon emissions are population, energy intensity, energy structure, production efficiency, technical level, and so on. After the test for multicollinearity using ordinary least squares (OLS) regression model, the explanatory variables chosen to explicate the spatial interaction mechanism of carbon intensity in China's construction industry are: energy intensity, production efficiency, and labor input. The specific definition of variables is provided here: energy intensity denotes the ratio of total energy consumption and construction area, which could reflect the technical effects on carbon emissions. The empirical results of Cheng et al. [29] indicated that energy intensity was one of the main factors of carbon intensity in China. Production efficiency refers to the ratio of the construction industry output values and construction practitioners, which certainly plays an important role in carbon productivity growth [13]. Labor input is the proportion of construction practitioners to total population, which reflects the level of labor resource input and cannot be neglected in a traditional labor-intensive sector. Almost all of the data for the variables is derived from the provincial statistical yearbook.

\section{Methods}

General research for spatial econometrics is usually divided into two steps [10]. Step one is to adopt a spatial dependence analysis of the dependent variable in order to examine whether there is spatial dependence. In this step, this paper undertakes the global and local spatial autocorrelation to reveal the spatial characteristic of carbon intensity. The second step is to choose an appropriate econometric model. A spatial econometric model should be established when there is spatial dependence, otherwise, the general econometric model could be effective.

\section{Global Spatial Autocorrelation}

The global spatial autocorrelation of China's carbon intensity in the construction industry can be examined by global Moran's I, which can be given as:

$$
I=\frac{n \sum_{i=1}^{n} \sum_{j=1}^{n} \omega_{i j}\left(x_{i}-\bar{x}\right)\left(x_{j}-\bar{x}\right)}{\sum_{i=1}^{n} \sum_{j=1}^{n} \omega_{i j} \sum_{i=1}^{n}\left(x_{i}-\bar{x}\right)^{2}}
$$

$\ldots$ where $n$ is the number of provinces, $x_{i}$ and $x_{j}$ denote the carbon intensity in construction industry of provinces $i$ and $j$, respectively, $\bar{x}$ refers to the average value of $x$, and $\omega_{i j}$ is the spatial weight matrix, which can be defined as the spatial neighboring relationship between each geographical unit. This paper uses the binary contiguity matrix with queen contiguity. If the $i$ th province is adjacent to the $j$ th province, the matrix elements $\omega_{i j}=1$, otherwise for $\omega_{i j}=0$. The value of the global Moran's I is between -1 and 1. Positive global Moran's I values mean positive spatial dependence, and the closer these values are to 1 , the greater the spatial clustering in the pattern. Negative Moran's I values mean negative spatial dependence the closer these values are to -1 , the greater the spatial dispersion in the pattern. A zero value indicates that there is no spatial autocorrelation and the carbon intensity exhibits a random spatial distribution.

\section{Local Spatial Autocorrelation}

The global Moran's I test can only evaluate the overall pattern and trend, but does not reveal spatial interaction of individual units. In order to deal with this issue, this paper adopts local spatial autocorrelation to further test local clustering at the provincial scale [31]. The local spatial autocorrelation analysis consists of the calculation of local Moran's I. For province $i$, local Moran's I is defined as: 


$$
I_{i}=\frac{\left(x_{i}-\bar{x}\right)}{s^{2}} \sum_{i \neq j} \omega_{i j}\left(x_{j}-\bar{x}\right)
$$

...where $x_{i}$ is the carbon intensity in construction industry of the variable $x$ at province $i, \bar{x}$ is the average value of $x, x_{j}$ is the carbon intensity in construction industry of the variable $x$ at all the other provinces (where $i \neq j$ ), $s^{2}$ is the variance of variable $x$, and $\omega_{i j}$ is a spatial weight matrix that can be defined as the spatial adjacent relations between provinces $i$ and $j$.

Positive local Moran's I means that the province has similarly higher or lower values as neighboring provinces, thus the provinces show spatial clustering. The spatial clustering includes $\mathrm{HH}$ clustering (provinces with high values are environed by neighboring provinces with high values) and LL clustering (provinces with low values are environed by neighboring provinces with low values).

Negative local Moran's I implies that the value of one province is clearly different from the values of neighboring provinces, which can be described as spatial outliers. Spatial outliers are those values that are obviously different from the values of their surrounding locations [32]. Spatial outliers include HL clustering (provinces with high values are environed by neighboring provinces with low values) and LH clustering (provinces with low values are environed by neighboring provinces with high values).

\section{Geographically Weighted Regression (GWR)}

Standard non-spatial regression analysis is predicated on the assumption that the relationship between the explanatory variables and the dependent variable is spatially stationary, and that the spatial variability includes spatial dependence and spatial heterogeneity [33]. Positive autocorrelation shows that objects with similar geographical locations have greater similarity and vice versa [34]. As a spatial econometric model, geographically weighted regression (GWR) is used in this paper. GWR is a technique that extends the general linear regression model, but the regression model includes the spatial attributes of the data [35-36]. The GWR model is specified as:

$$
y_{i}=\beta_{0}\left(u_{i}, v_{i}\right)+\sum_{k} \beta_{k}\left(u_{i}, v_{i}\right) x_{i k}+\varepsilon_{i}
$$

...where $\left(u_{i}, v_{i}\right)$ represents the geographical coordinates of province $i$, and $\beta_{k}\left(u_{i}, v_{i}\right)$ denotes the regression coefficient related to the $k$ th explanatory variable for province $i$. The regression coefficient of province $i$ can be estimated based on the spatial weighting function. Fotheringham et al. [37] suggested that a weighting function can be used as a monotone decreasing and continuous function of spatial distance. Gauss's function is used in this study.

$$
\omega_{i j}=\exp \left[-\left(d_{i j} / b\right)^{2}\right]
$$

$\ldots$ where $b$ refers to bandwidth and $d_{i j}$ denotes the distance between province $i$ and province $j$. Bowman [38] proposed a cross-validation $(\mathrm{CV})$ method, which can be used to determine the appropriate bandwidth $b$.

$$
C V=\sum_{i=1}^{n}\left[y_{i}-\hat{y}_{\neq i}(b)\right]^{2}
$$

In this formula $\hat{y} \neq i$ represents the estimated value for $y_{i}$, which is the $i$ th observation value that is excluded in the regression process. When the $C V$ value reaches the minimum, the corresponding $b$ is the appropriate bandwidth.

\section{Results and Discussion}

\section{Spatial Distribution Characteristics}

Fig. 1 summarizes the provincial carbon intensity in China's construction industry for the years 2005, 2008, 2011, and 2014. From 2005 to 2014, the carbon intensity of each province decreased year after year. However, there is an obvious difference of carbon intensity at the provincial scale. For example, the results show that provinces with the highest carbon intensities were Shanxi, Inner Mongolia Autonomous Region, and Xinjiang Uygur Autonomous Region in 2014, and their carbon intensities were almost six times those of Shanghai, Fujian, and Hubei provinces.

Because of space limitations, this paper lists the graphs of provincial carbon intensity in China's construction industry for the years 2005, 2008, 2011, and 2014. The spatial pattern of carbon intensity through time is displayed in Fig. 2. Provinces with low carbon intensities are clustered in the southeastern coastal regions, while provinces with higher carbon intensities are clustered in the northern and western inland areas of China. The spatial disparity and clustering of carbon intensity in the construction industry reveals spatial dependence. To

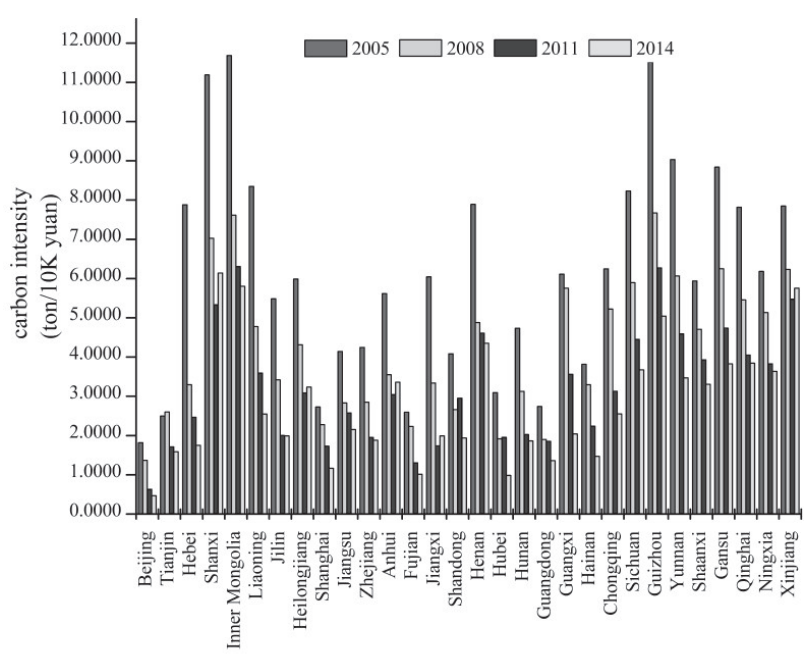

Fig. 1. Provincial carbon intensity in the construction industry over time. 

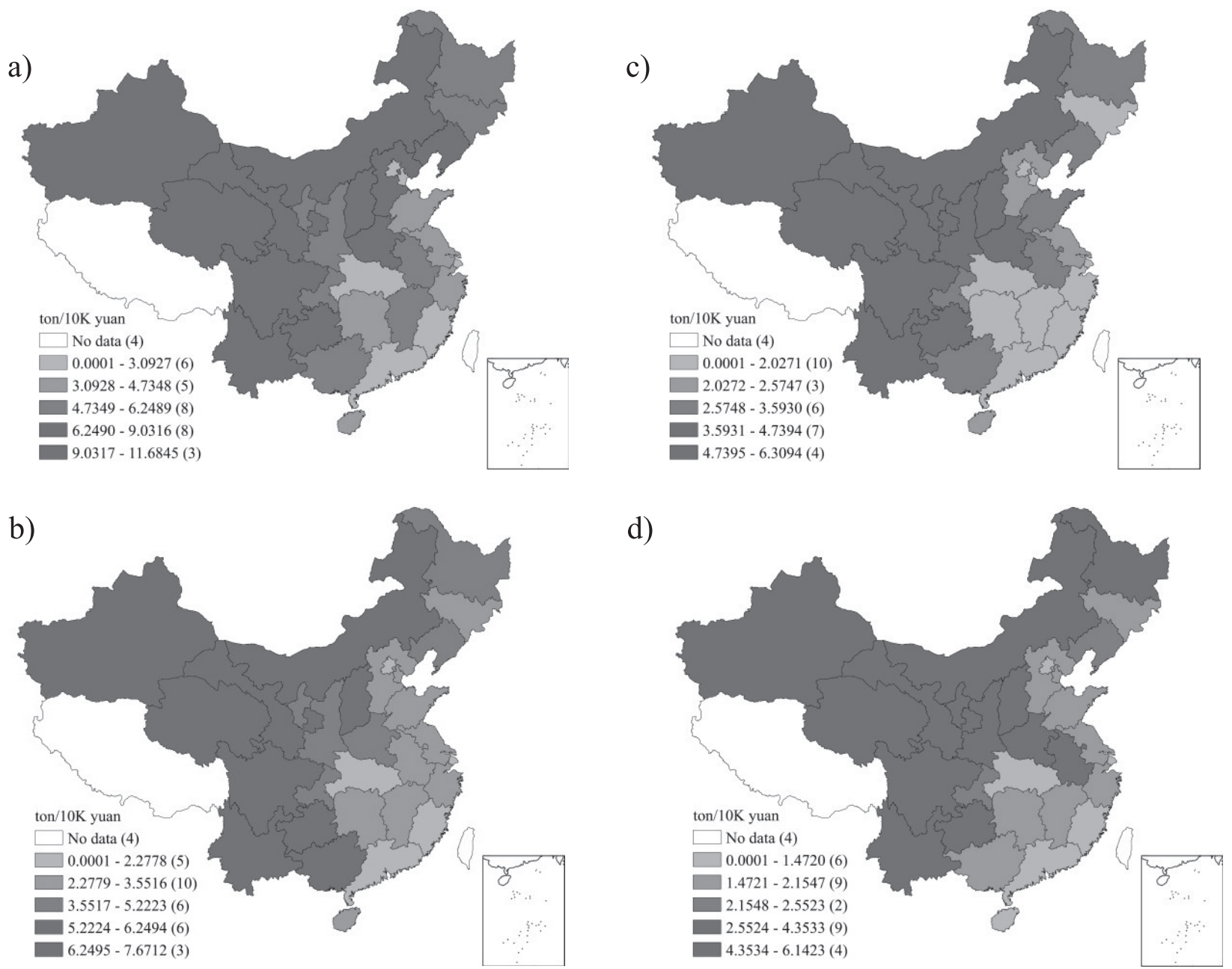

Fig. 2. Spatial pattern of China's carbon intensity in the construction industry. a) carbon intensity in 2005 , b) carbon intensity in 2008 , c) carbon intensity in 2011, d) carbon intensity in 2014 .

recognize spatial clustering this study tried to use global Moran's I and local Moran's I to examine the spatial autocorrelation of provincial carbon intensity in China's construction industry.

\section{Global Spatial Autocorrelation}

Table 1 shows the global Moran I of provincial carbon intensity and its significance in China's construction industry from 2005 to 2014 . The test shows that the annual values are all above 0 and that carbon intensity exhibits spatial autocorrelation at the $1 \%$ significance level for the whole period, which reveals that carbon intensity in this sector shows significant spatial clustering. Provinces with low carbon intensities tend to cluster together, whereas provinces with high carbon intensities cluster together. Furthermore, Fig. 3 indicates that the global Moran I of carbon intensity has a downward trend with a small fluctuation from 0.509 to 0.365 in this period, which reveals that the spatial clustering degree of provincial carbon intensity in the construction industry has a decreasing tendency.

However, there is a limitation in the global Moran I test, which can only evaluate the overall pattern and trend. If some provinces have a positive spatial autocorrelation and others have a negative spatial autocorrelation, then the

Table 1. Global Moran I of China's carbon intensity in the construction industry.

\begin{tabular}{|c|c|c|c|}
\hline Year & Moran I & P-value & $\mathrm{Z}$ \\
\hline 2005 & 0.387 & 0.003 & 3.496 \\
\hline 2006 & 0.382 & 0.001 & 3.480 \\
\hline 2007 & 0.440 & 0.001 & 4.099 \\
\hline 2008 & 0.509 & 0.001 & 4.537 \\
\hline 2009 & 0.458 & 0.002 & 4.250 \\
\hline 2010 & 0.438 & 0.001 & 3.936 \\
\hline 2011 & 0.461 & 0.001 & 4.352 \\
\hline 2012 & 0.405 & 0.001 & 3.818 \\
\hline 2013 & 0.412 & 0.001 & 3.870 \\
\hline 2014 & 0.365 & 0.001 & 3.467 \\
\hline
\end{tabular}




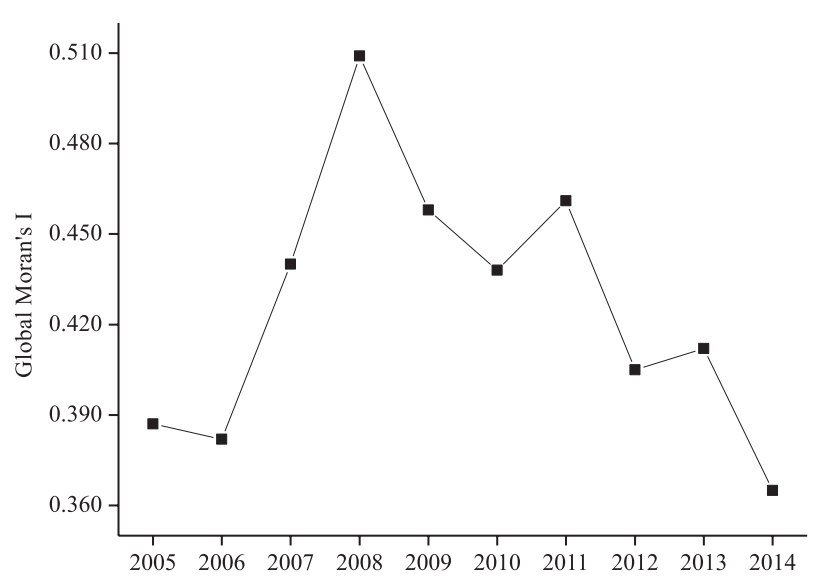

Fig. 3. Change of Global Moran I of China's carbon intensity in the construction industry (2005-2014).

effects could offset each other. On this occasion, global Moran I may reveal non-spatial autocorrelation. On this account, this paper uses the local Moran I to further test spatial clustering among the provinces.

\section{Local Spatial Autocorrelation}

To test the local spatial autocorrelation, this paper employs a Moran scatter plot analysis. There are four points in time - 2005, 2008, 2011, and 2014 - to show the Moran scatter plots of provincial carbon intensity in China's construction industry, which are displayed in Fig. 4. The horizontal axis of these scatter plots refers to carbon intensity in the construction industry, while the vertical axis refers to the corresponding spatial lag. The four quadrants in the Moran scatter plot are described as follows. Quadrant I is HH clustering, which means provinces with high carbon intensities are environed by neighboring provinces with high carbon intensities. Quadrant II is LH clustering, which means provinces with low carbon intensities are environed by neighboring provinces with high carbon intensities. Quadrant III is LL clustering, which means provinces with low carbon intensities are environed by neighboring provinces with

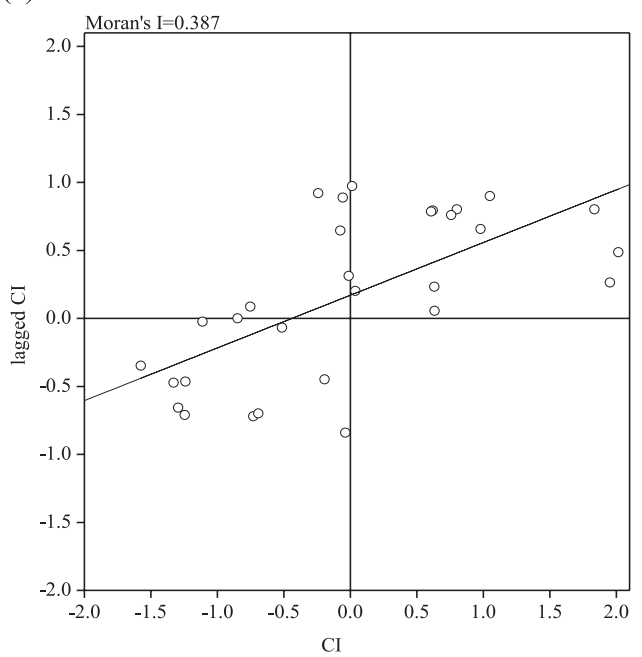

(b)

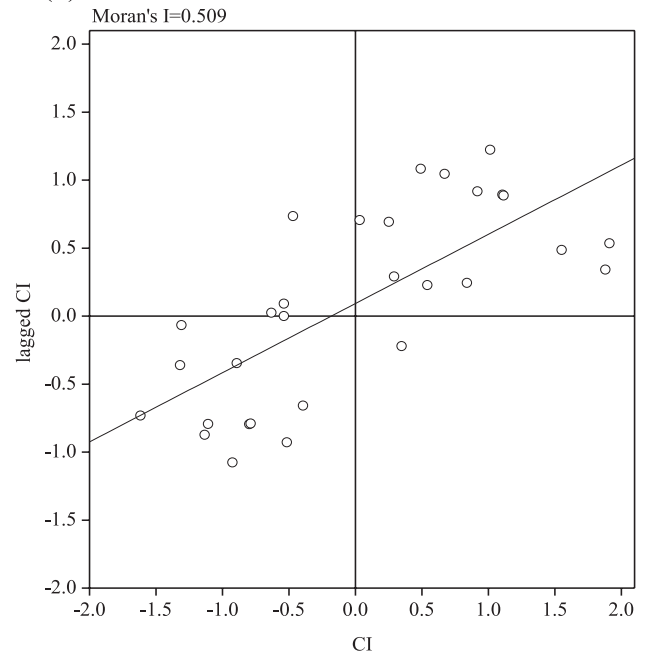

c)

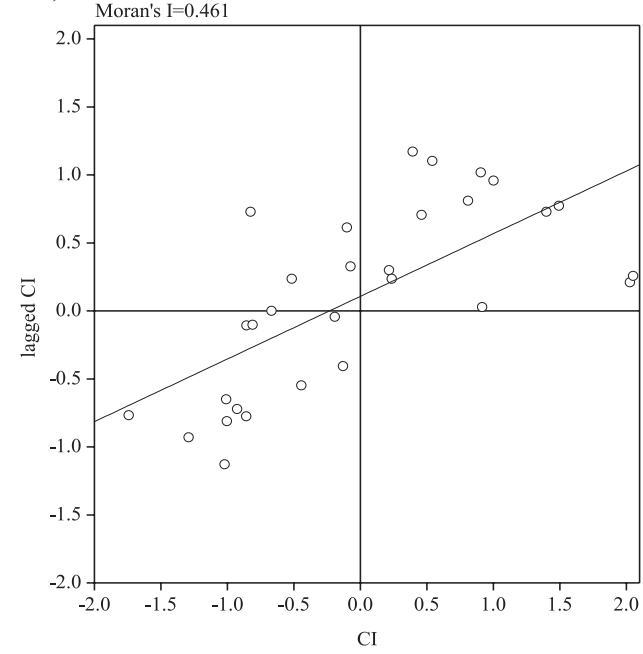

d)

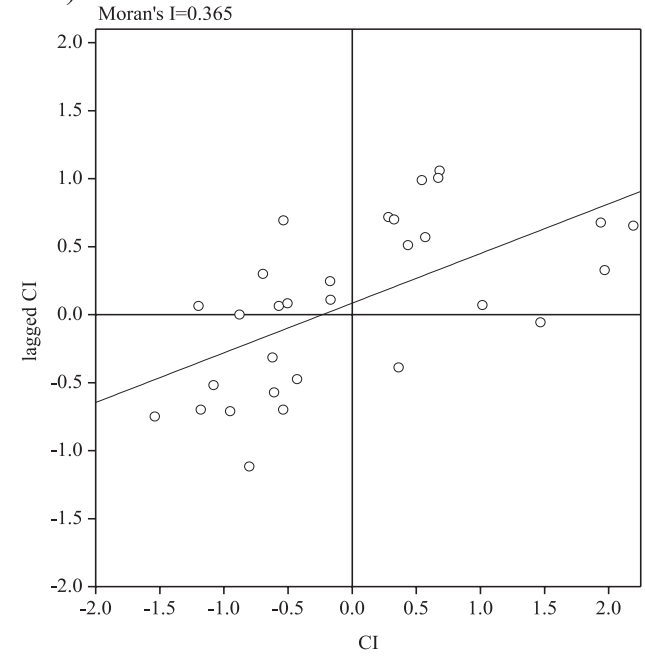

Fig. 4. Moran scatter plots of China's provincial carbon intensity in the construction industry. a) Moran scatter plots in 2005, b) Moran scatter plots in 2008, c) Moran scatter plots in 2011, d) Moran scatter plots in 2014. 
Table 2. Scatter distribution of China's carbon intensity in the construction industry over time.

\begin{tabular}{|c|c|c|c|}
\hline Year & Quadrant & Number & Provinces \\
\hline \multirow{4}{*}{2005} & $\mathrm{I}(\mathrm{HH})$ & 13 & $\begin{array}{c}\text { Hebei, Shanxi, Inner Mongolia, Liaoning, Henan, Chongqing, Sichuan, Guizhou, Yunnan, } \\
\text { Gansu, Qinghai, Ningxia, Xinjiang }\end{array}$ \\
\hline & $\mathrm{II}(\mathrm{LH})$ & 5 & Shandong, Heilongjiang, Jilin, Guangxi, Shaanxi \\
\hline & III(LL) & 11 & $\begin{array}{c}\text { Beijing, Tianjin, Shanghai, Jiangsu, Zhejiang, Fujian, Guangdong, Hubei, Hunan, Anhui, } \\
\text { Jiangxi }\end{array}$ \\
\hline & IV(HL) & 0 & \\
\hline \multirow{4}{*}{2008} & $\mathrm{I}(\mathrm{HH})$ & 14 & $\begin{array}{c}\text { Shanxi, Inner Mongolia, Liaoning, Heilongjiang, Guangxi, Chongqing, Sichuan, Guizhou, } \\
\text { Yunnan, Shaanxi, Gansu, Qinghai, Ningxia, Xinjiang }\end{array}$ \\
\hline & $\mathrm{II}(\mathrm{LH})$ & 3 & Jilin, Hebei, Hunan \\
\hline & III(LL) & 11 & $\begin{array}{c}\text { Beijing, Tianjin, Shanghai, Jiangsu, Zhejiang, Anhui, Fujian, Jiangxi, Guangdong, Shandong, } \\
\text { Hubei }\end{array}$ \\
\hline & $\mathrm{IV}(\mathrm{HL})$ & 1 & Henan \\
\hline \multirow{4}{*}{2011} & $\mathrm{I}(\mathrm{HH})$ & 13 & $\begin{array}{l}\text { Shanxi, Inner Mongolia, Liaoning, Henan, Guangxi, Sichuan, Guizhou, Yunnan, Shaanxi, } \\
\text { Gansu, Qinghai, Ningxia, Xinjiang }\end{array}$ \\
\hline & $\mathrm{II}(\mathrm{LH})$ & 4 & Jilin, Hebei, Heilongjiang, Chongqing \\
\hline & III(LL) & 12 & $\begin{array}{c}\text { Beijing, Tianjin, Shanghai, Jiangsu, Zhejiang, Fujian, Jiangxi, Guangdong, Shandong, Hubei, } \\
\text { Hunan, Anhui }\end{array}$ \\
\hline & IV(HL) & & \\
\hline \multirow{4}{*}{2014} & $\mathrm{I}(\mathrm{HH})$ & 11 & $\begin{array}{l}\text { Shanxi, Inner Mongolia, Heilongjiang, Henan, Sichuan, Yunnan, Shaanxi, Gansu, Qinghai, } \\
\text { Ningxia, Xinjiang }\end{array}$ \\
\hline & $\mathrm{II}(\mathrm{LH})$ & 7 & Jilin, Hebei, Shandong, Hubei, Guangxi, Liaoning, Chongqing \\
\hline & III(LL) & 9 & Beijing, Tianjin, Shanghai, Jiangsu, Zhejiang, Fujian, Jiangxi, Hunan, Guangdong \\
\hline & IV(HL) & 2 & Anhui, Guizhou \\
\hline
\end{tabular}

low carbon intensities. Quadrant IV is HL clustering, which means provinces with high carbon intensities are environed by neighboring provinces with low carbon intensities. Quadrants I and III reveal positive spatial autocorrelation characteristics, while quadrants II and IV reveal negative spatial autocorrelation characteristics.

In 2005 the number of provinces with $\mathrm{HH}$ clustering and LL clustering were 13 and 11, respectively, which accounted for $80 \%$ of all the provinces, whereas the provinces with HL clustering and LH clustering accounted for $20 \%$ of all the provinces, which showed that spatial dependence and dispersion of carbon intensity in the construction industry existed simultaneously at the provincial scale. In 2008 the number of provinces with
HH clustering increased by 1 compared with 2005, which indicated that the spatial clustering degree of the provinces with higher carbon intensity tended to increase in 2005-2008, and regional disparity of carbon intensity at the provincial level tended to be further reduced during this period. In 2011 the number of provinces with LL clustering decreased by 1 compared with 2008, while that of the provinces with LL clustering increased by 1. In 2014 the number of provinces with $\mathrm{HH}$ clustering decreased by 2 compared with 2011, while that of the provinces with LL clustering decreased by 3, which indicated that the spatial clustering degree of the provinces with high carbon intensity had a downward tendency in 2011-2014, and the spatial clustering characteristics of carbon intensity among the provinces

Table 3. Entire estimation results of GWR.

\begin{tabular}{|c|c|c|c|c|}
\hline Indicator & 2005 & 2008 & 2011 & 2014 \\
\hline $\mathrm{R}^{2}$ & 0.837 & 0.755 & 0.647 & 0.616 \\
\hline $\mathrm{R}^{2}$ adjusted & 0.821 & 0.730 & 0.612 & 0.576 \\
\hline Residual Squares & 2.831 & 3.057 & 4.168 & 5.033 \\
\hline Bandwidth & $38,124,888.010$ & $38,124,888.010$ & $38,124,888.010$ & $10,319,760.182$ \\
\hline AICc & 24.131 & 26.744 & 37.283 & 43.912 \\
\hline
\end{tabular}


appeared to weaken in this period. As a whole, the spatial clustering degree of China's provincial carbon intensity in the construction industry tended to weaken during the observation period.

The results of the Moran scatter plots in 2005, 2008, 2011, and 2014 are reported in Table 2. Provinces with $\mathrm{HH}$ clustering are distributed mainly in the northern and western areas of China, while provinces with LL clustering are centralized mainly in the southeastern coastal areas. This further indicates that there is a significant spatial clustering in province-level carbon intensity.

The results of global Moran I and local Moran I analysis indicate that there is significant spatial autocorrelation of China's provincial carbon intensity in the construction industry for the period of observation. Spatial autocorrelation among the provinces of carbon intensity implies that the classical econometric models would lead to estimation bias on regression results. Therefore, this paper examines the drivers of carbon emissions based on the geographically weighted regression (GWR) model,

Table 4. Result of GWR in 2014.

\begin{tabular}{|c|c|c|c|c|c|c|c|}
\hline Province & Local R ${ }^{2}$ & Predicted & $\begin{array}{c}\text { Energy } \\
\text { intensity }\end{array}$ & $\begin{array}{c}\text { Production } \\
\text { efficiency }\end{array}$ & Labor input & Residual & $\begin{array}{c}\text { Standard } \\
\text { Error }\end{array}$ \\
\hline Heilongjiang & 0.610 & 1.358 & 0.255 & -0.246 & -0.576 & -0.184 & 0.391 \\
\hline Xinjiang & 0.618 & 1.336 & 0.255 & -0.249 & -0.582 & 0.414 & 0.391 \\
\hline Shanxi & 0.612 & 1.417 & 0.253 & -0.246 & -0.577 & 0.398 & 0.390 \\
\hline Ningxia & 0.613 & 1.174 & 0.253 & -0.247 & -0.578 & 0.117 & 0.399 \\
\hline Shandong & 0.611 & 0.816 & 0.252 & -0.246 & -0.576 & -0.154 & 0.403 \\
\hline Henan & 0.611 & 0.719 & 0.252 & -0.246 & -0.576 & 0.752 & 0.397 \\
\hline Jiangsu & 0.610 & 0.098 & 0.251 & -0.246 & -0.575 & 0.669 & 0.382 \\
\hline Anhui & 0.610 & 0.973 & 0.251 & -0.246 & -0.576 & 0.238 & 0.403 \\
\hline Hubei & 0.612 & 0.490 & 0.251 & -0.246 & -0.576 & -0.505 & 0.396 \\
\hline Zhejiang & 0.609 & -0.105 & 0.250 & -0.245 & -0.575 & 0.737 & 0.366 \\
\hline Jiangxi & 0.610 & 0.846 & 0.250 & -0.245 & -0.575 & -0.157 & 0.403 \\
\hline Hunan & 0.611 & 0.697 & 0.250 & -0.246 & -0.576 & -0.074 & 0.403 \\
\hline Yunnan & 0.614 & 1.318 & 0.250 & -0.246 & -0.578 & -0.074 & 0.395 \\
\hline Guizhou & 0.613 & 1.460 & 0.250 & -0.246 & -0.577 & 0.157 & 0.388 \\
\hline Fujian & 0.610 & 0.104 & 0.250 & -0.245 & -0.575 & -0.090 & 0.389 \\
\hline Guangxi & 0.612 & 1.122 & 0.249 & -0.246 & -0.576 & -0.408 & 0.394 \\
\hline Guangdong & 0.611 & 0.950 & 0.249 & -0.245 & -0.575 & -0.641 & 0.399 \\
\hline Hainan & 0.611 & -0.020 & 0.248 & -0.245 & -0.575 & 0.406 & 0.206 \\
\hline Jilin & 0.610 & 1.074 & 0.254 & -0.246 & -0.576 & -0.385 & 0.401 \\
\hline Liaoning & 0.610 & 0.893 & 0.253 & -0.246 & -0.576 & 0.042 & 0.394 \\
\hline Tianjin & 0.611 & 0.450 & 0.253 & -0.246 & -0.576 & 0.013 & 0.387 \\
\hline Qinghai & 0.616 & 1.460 & 0.253 & -0.248 & -0.580 & -0.113 & 0.388 \\
\hline Gansu & 0.614 & 1.174 & 0.253 & -0.247 & -0.579 & 0.168 & 0.399 \\
\hline Shaanxi & 0.613 & 0.985 & 0.252 & -0.246 & -0.577 & 0.210 & 0.401 \\
\hline $\begin{array}{c}\text { Inner } \\
\text { Mongolia }\end{array}$ & 0.612 & 1.533 & 0.254 & -0.247 & -0.578 & 0.225 & 0.387 \\
\hline Chongqing & 0.613 & 0.550 & 0.251 & -0.246 & -0.577 & 0.387 & 0.399 \\
\hline Hebei & 0.611 & 1.071 & 0.253 & -0.246 & -0.577 & -0.512 & 0.399 \\
\hline Shanghai & 0.609 & 0.470 & 0.251 & -0.245 & -0.575 & -0.317 & 0.391 \\
\hline Beijing & 0.611 & 0.195 & 0.253 & -0.246 & -0.577 & -0.953 & 0.359 \\
\hline Sichuan & 0.614 & 0.970 & 0.251 & -0.247 & -0.578 & 0.331 & 0.403 \\
\hline
\end{tabular}


which is preferable to classical econometric models since it can capture spatial-dependent relationships.

\section{Geographically Weighted Regression (GWR)}

GWR can clearly identify the level of impact of the variables on construction industry carbon intensity in each province. Moreover, GWR is used to recognize the spatial relationship between variables and carbon intensity in the construction industry. The whole estimation results of GWR are reported in Table 3, including the values of $\mathrm{R}^{2}$, the appropriate bandwidth, and the corrected Akaike information criterion (AICc) in each year.

Due to space limitations, this paper only lists the results of GWR in 2014, which is shown in Table 4. The GWR model displayed the regression equation of each province combined with Figs 5-7. The results can fully reveal the regional disparity of provincial carbon intensity in the construction industry, since they are based on considering spatial interaction effects among the provinces. From the perspective of influence

a)

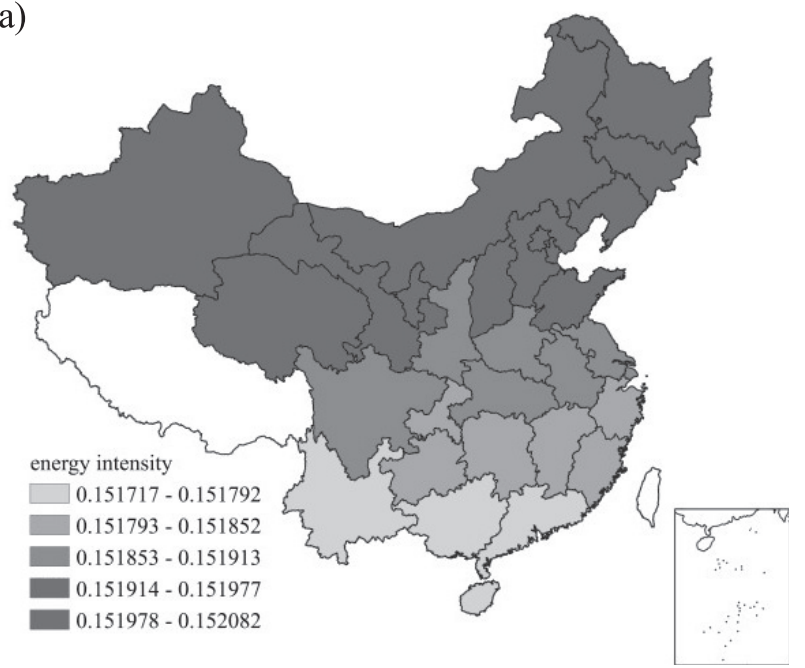

b)

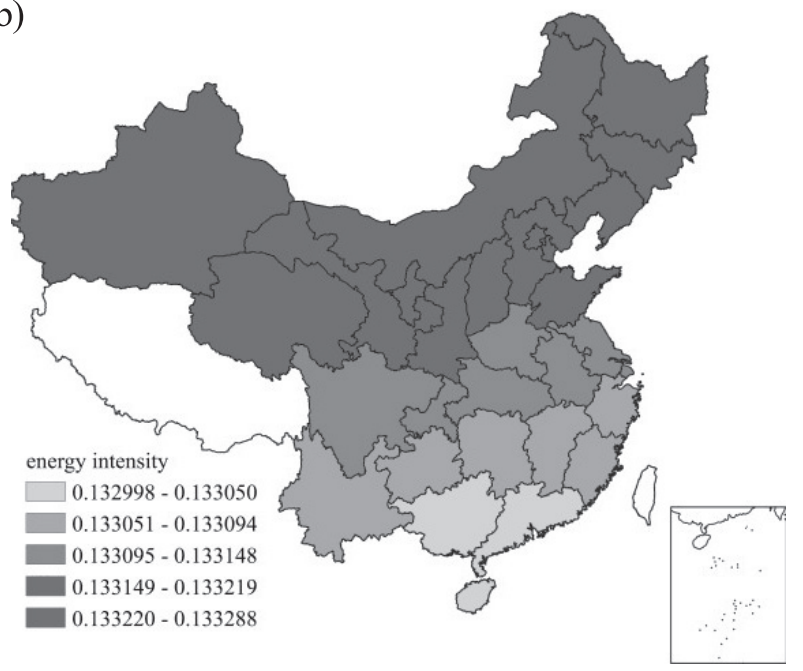

degrees of variables, the population of the construction industry has the largest effect on carbon emissions, followed by energy intensity and production efficiency. The results of GWR also show that carbon intensity change has a strong negative correlation with the population of construction industry and production efficiency while carbon intensity is positively affected by energy intensity. The impact of the driving factors on carbon emissions in each province is analyzed as follows.

In terms of energy intensity, there is little difference in elastic coefficients of contiguous provinces from the regression coefficients among the years, as shown in Fig. 5. Therefore, the effect of energy intensity on carbon emissions reveals an evident spatial dependence effect. Energy intensity plays a positive role in carbon intensity during the observation period. Moreover, the regression coefficients decreased at first and then increased with time, and the minimum of coefficients occurred in 2008. Before 2008, the impact of economic growth was obviously increased because China was experiencing a c)

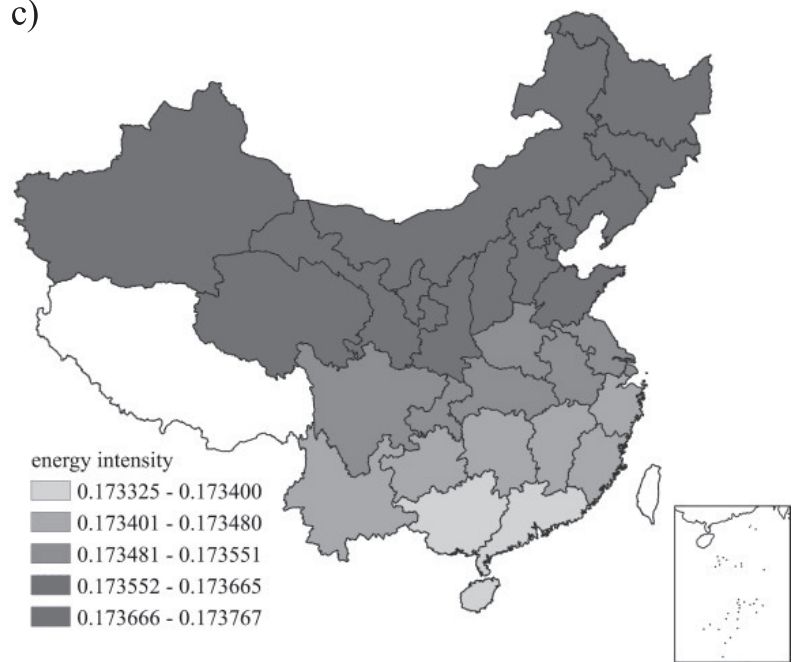

d)

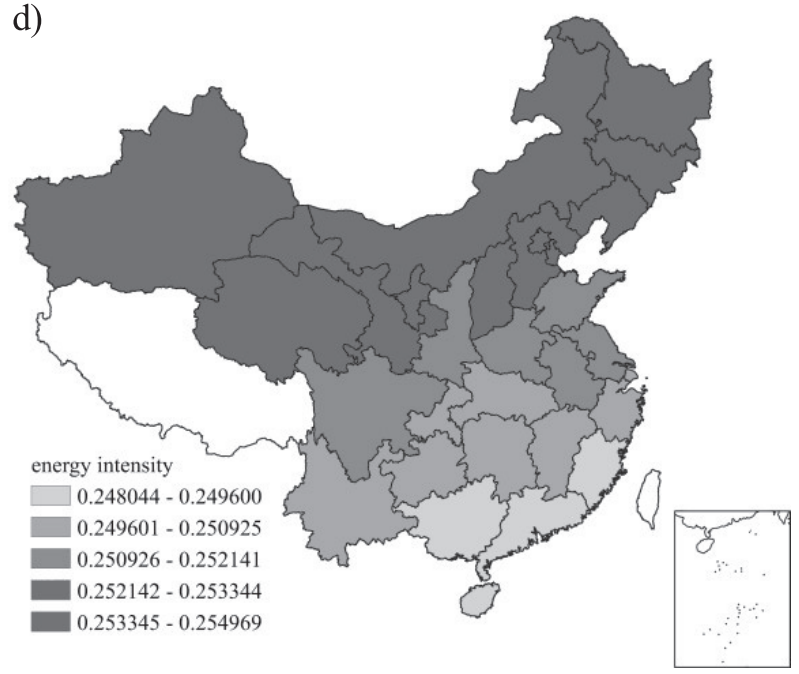

Fig. 5. Regression coefficients of energy intensity over four years. a) regression coefficients in 2005, b) regression coefficients in 2008 , c) regression coefficients in 2011, d) regression coefficients in 2014. 
rapid economic growth, which weakened the effect of energy intensity on carbon emissions. Improvement of technology impelled the effect on carbon emissions to increase since 2008. From 2005 to 2014, the provinces with great influence of energy intensity were Xinjiang, Inner Mongolia, Heilongjiang, and Jilin, which are located in midwestern and northeastern China. This suggests that the technical level in these areas has a great promotional effect on the energy-saving and emissions-reduction work. The main reason for great influence is that carbon emissions in the underdeveloped areas are liable to be affected by improvement of technology. Under a common goal of construction, the areas with relatively backward development and lower technical level would consume more energy and produce large quantities of carbon dioxide. In the meantime, provinces with little influence on energy intensity were centralized in southeastern China, such as Guangdong, since the potential of carbon emissions reduction has been weakened in the present technical level. In conclusion, carbon emissions can be curbed by improving energy utilization efficiency in the underdeveloped areas, whereas a technology update is key to reducing carbon emissions in the relatively advanced region.

Fig. 6 shows the results of the production efficiency factor in influencing carbon intensity change in China's construction industry, which indicates that the influence on carbon emissions displays significant spatial clustering characteristics as a whole. There is a negative correlation between production efficiency and carbon emissions. The coefficients fluctuated in the range of 0.239135 0.318713, but showed a downtrend, which means that the effect intensity of production efficiency was slightly weaker. From 2005 to 2014, the effect of production efficiency on $\mathrm{CO}_{2}$ emissions gradually shifted to the areas of midwestern China. In 2014 the provinces with large coefficients are distributed mainly throughout the midwestern provinces, including Xinjiang, Inner Mongolia, and Gansu, whereas the provinces with relatively small coefficients are centralized in southeastern provinces, including Guangdong, Zhejiang, and Jiangsu. As can be seen from Fig. 6, production efficiency has a)

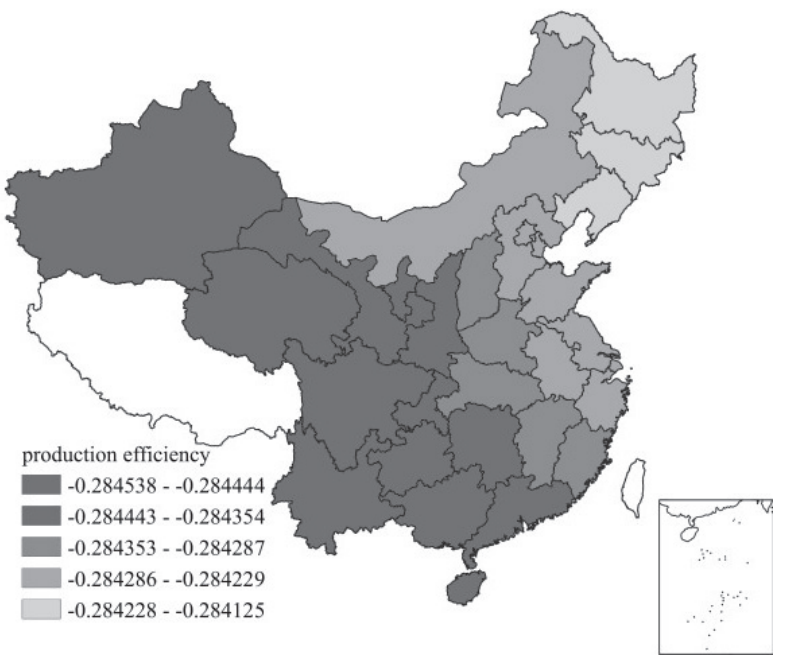

b)

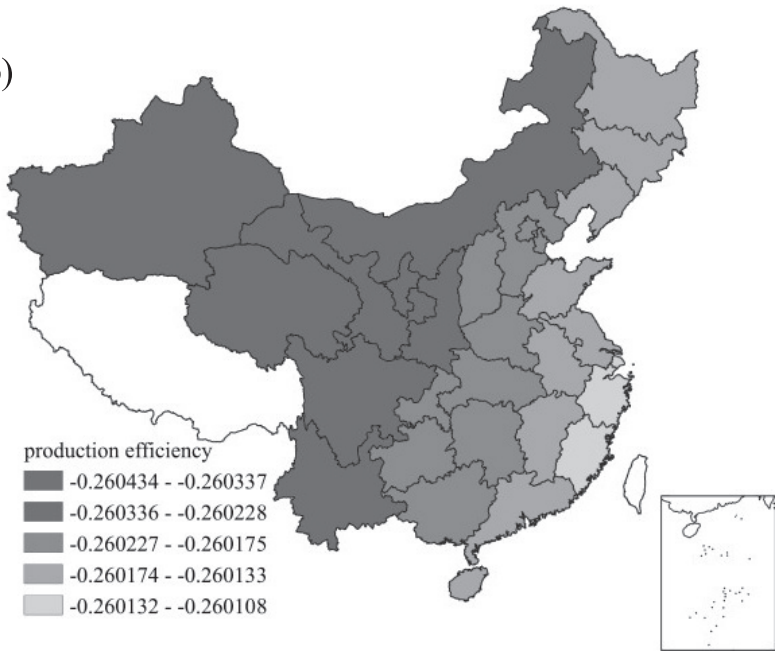

c)

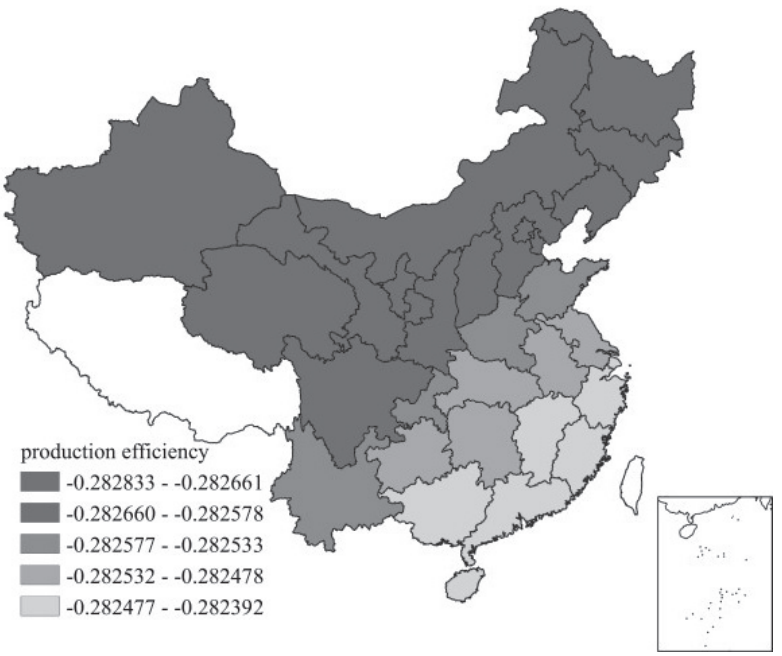

d)

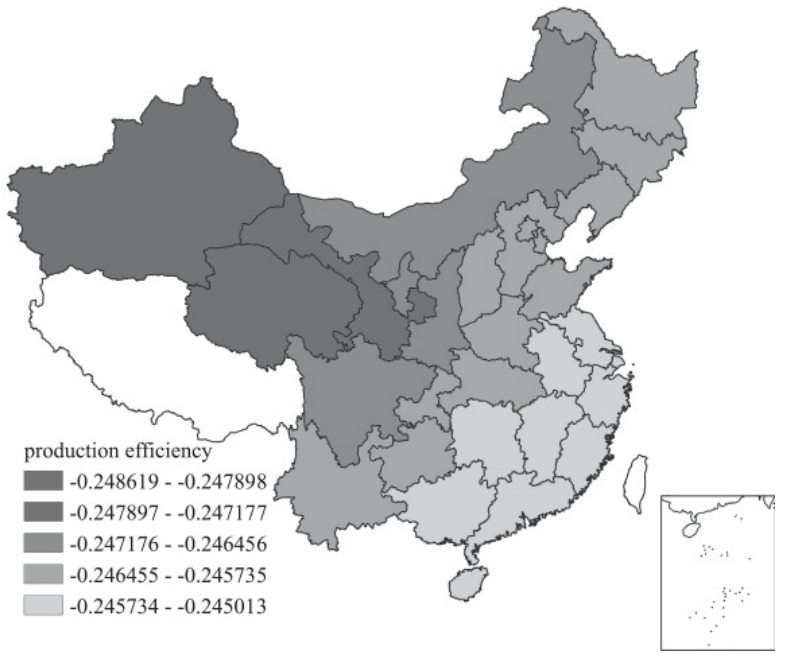

Fig. 6. Regression coefficients of production efficiency over four years. a) regression coefficients in 2005, b) regression coefficients in 2008, c) regression coefficients in 2011, d) regression coefficients in 2014. 
greater impact on carbon emissions of the midwestern provinces than the eastern provinces. In the development of western China, the economic development in the midwestern provinces demands many public facilities due to the relatively backward development and lower urbanization level, which leads to a gap in talent in the construction industry. This means that a corresponding increase in production efficiency has a more significant impacts on emissions-reduction in the midwestern provinces. Therefore, improving production efficiency is one of the effective methods to reduce carbon emissions in these areas. However, the southeastern provinces have mature construction technology and rich experience in construction management with the rapid development of the economy. In these circumstances, production efficiency plays a limited part in emissions reduction, so it's necessary to develop advanced technology, such as building information modeling (BIM), when promoting carbon emissions reduction in these regions.

As shown in Fig. 7, labor input has a significant impact on carbon emissions compared with the other two factors and it displays obvious spatial clustering characteristics. As a traditional labor-intensive industry, it is necessary for the construction industry to own a lot of practitioners. The influence of the construction industry workers on carbon emissions cannot be neglected, which may be caused by the liquidity of the construction industry. That is the reason why there is a large regression coefficient of labor input. The regression coefficients of labor input were negative throughout the whole period of observation, which means that labor input has had an inhibitory effect on carbon emissions. From the global aspect, there was a downward trend, although the coefficients fluctuated in the range of $0.568930 \sim 0.641564$. This indicates that the effect intensity of the labor input appeared to weaken a little. From 2005 to 2014, the effect of the labor input on carbon emissions gradually shifted to the midwestern inland provinces. In 2014 the provinces with large elastic coefficients were Xinjiang, Inner Mongolia, Qinghai, Gansu, Ningxia, Sichuan, and other provinces of midwestern China, whereas the provinces with small a)

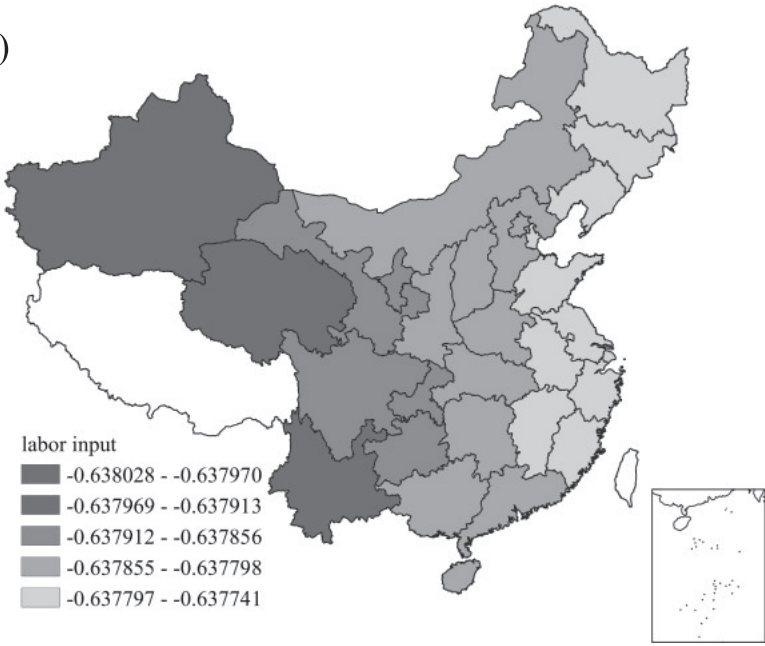

b)

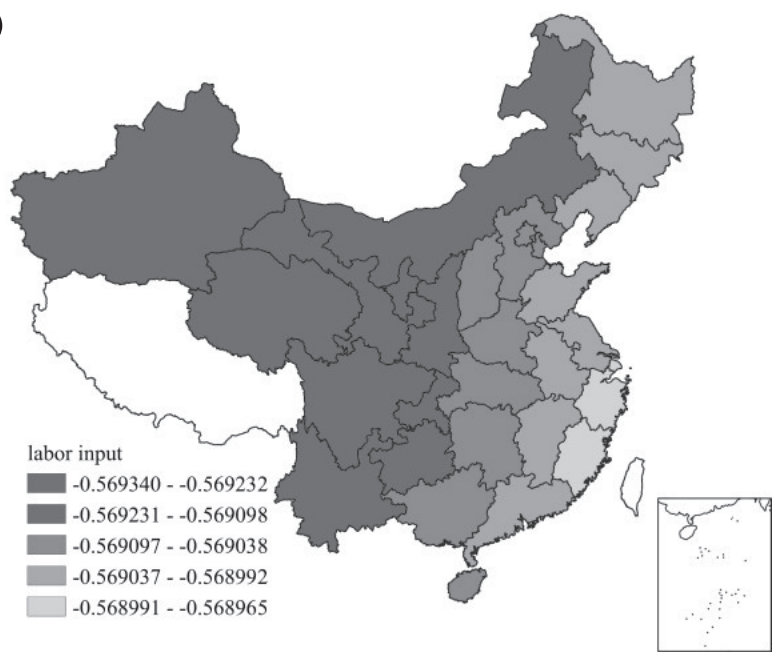

c)

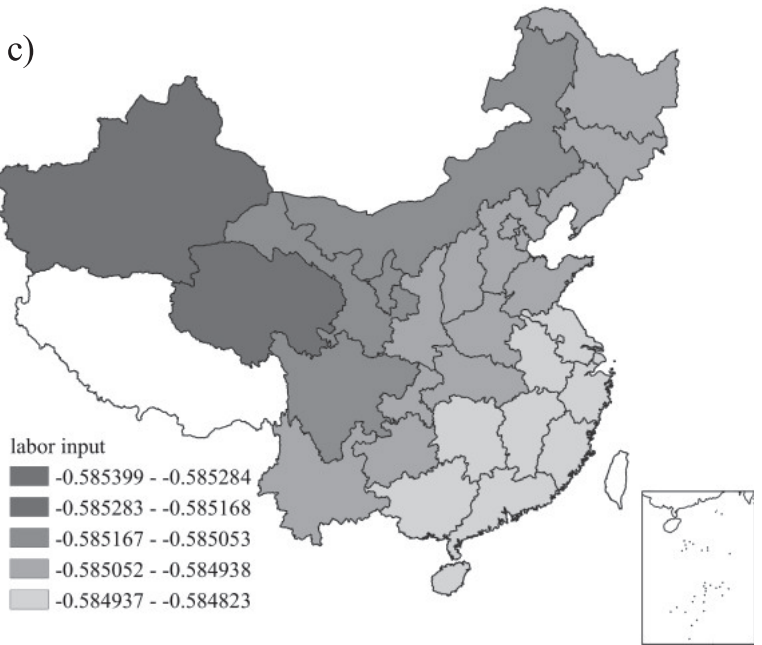

d)

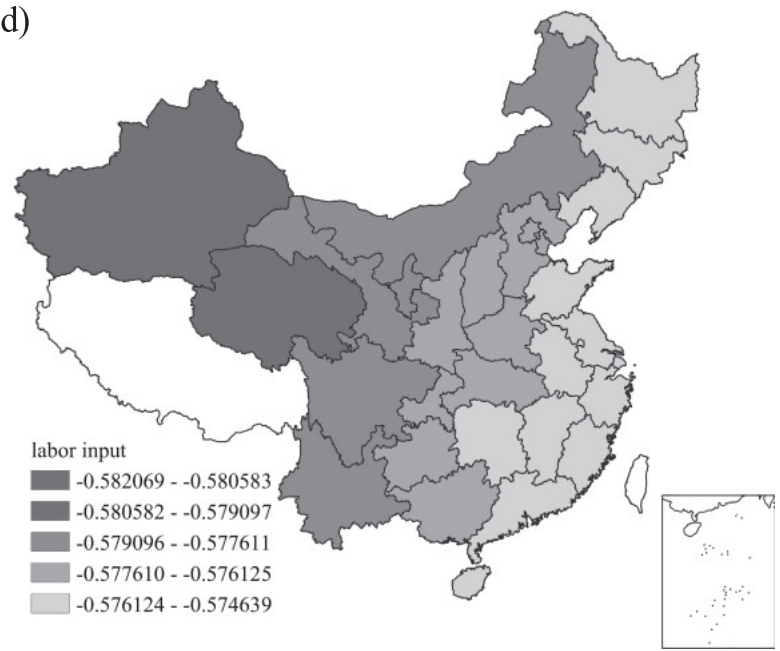

Fig. 7. Regression coefficients of labor input over four years. a) regression coefficients in 2005, b) regression coefficients in 2008 , c) regression coefficients in 2011, d) regression coefficients in 2014. 
coefficients are Guangdong, Zhejiang, Jiangsu, and other provinces in eastern China. It can also be seen from Figure 7 that labor input has a greater impact on $\mathrm{CO}_{2}$ emissions of the midwestern provinces than the eastern provinces, and the effects of the less developed regions are greater than developed regions. Urbanization is a strong motivation to promote development of the construction industry. Recently, urban infrastructure and transport network demand has been increasing rapidly with city population gathering especially for the midwestern region of China. Due to the lack of practitioners in the construction industry, increasing manpower in these areas can markedly facilitate the rise of efficiency, which has an obvious effect on emissions reduction. However, compared to the midwestern areas, increasing manpower input plays a limited role in reducing carbon emissions, which may be caused by developed building industries and abundant practitioner resources. This means that carbon emissions reduction is required to be combined with other methods in these areas.

\section{Conclusions}

Issues related to spatial autocorrelation cannot be neglected in the energy and environmental literature. Nevertheless, few studies have taken spatial dependence into account on carbon emissions reduction. This paper examines the spatiotemporal characteristics and spatial dependence of carbon intensity in China's construction industry at the regional level, and investigated the dominating factors of carbon intensity based on geographically weighted regression from the point of spatial effect.

Through the time distribution, the provincial carbon intensity in China's construction industry has been decreasing from 2005 to 2014. Judging from the spatial pattern, the empirical results reveal that the spatial distribution characteristics of carbon intensity in the construction industry can be described as "high in the north and east, lower in the south and east." From the view of global spatial autocorrelation, carbon intensity shows significant spatial clustering and the clustering degree has a decreasing tendency. In terms of local spatial autocorrelation, there is also a significant spatial cluste-ring in industrial carbon intensity among the provinces. Provinces with $\mathrm{HH}$ clustering are distributed principally in the northern and western areas of China, while provinces with LL clustering are centralized principally in the southeastern coastal regions. Local spatial autocorrelation further indicates that the spatial clustering degree of carbon intensity appeared to weaken in that period.

The estimation results of GWR analysis are more accurate than classical econometric models because of the spatial dependence relationships. This paper used the GWR method in order to avoid estimation bias from ignoring spatial dependence. The regression results suggest that energy intensity has a positive impact on provincial carbon intensity in the construction industry, whereas production efficiency and labor input have a negative impact. Moreover, the effect of production efficiency and labor input on carbon intensity appeared to weaken a little from 2005 to 2014, but the effect of energy intensity has an increasing tendency as a whole. As shown in Figs 5-7, these three factors have greater impact on carbon emissions of the midwestern provinces than the southeastern provinces as a whole, which is caused by the relatively backward development and lower urbanization level in the midwestern areas.

The empirical results have implications for energysaving and emissions-reduction policies. The regional disparity of carbon intensity in the construction industry remains serious. There is significant spatial disparity in the effect of energy intensity, production efficiency, and labor input on industrial carbon intensity, which shows an obvious spatial interaction. Therefore, it is essential to take regional characteristics into account when formulating and implementing policies that should be differentiated based on the level of technology and the progress of economic development in different provinces. The government should promote the exchange and sharing of technology, information, and resources across provinces and strengthen neighboring province development by making appropriate policies. The developed provinces and regions should undertake more responsibility of energy-saving and emissions reduction in the construction industry.

In the meantime, the midwestern and northeastern provinces depending highly on energy should make efforts to promote industrial restructuring and reduce the proportion of highly polluting energy such as coal in energy consumption. New energy industrialization and technology updates are pivotal for energy-saving and emissions reduction in these areas, especially new energy development and clean utilization technology of coal. The southeastern provinces should increase investment in the research of new construction materials and energies, such as developing the utilization of prefabricated materials as an alternative to traditional building materials.

Furthermore, carbon abatement in the construction industry basically depends on the new industrialization of construction, in which mainly BIM technology would be widely employed. The new industrialization of construction can effectively boost the supply of labor and improve production efficiency. BIM methodology could reduce carbon emissions and mitigate the effects of climate change by enhancing building energy efficiency and reducing total energy consumption [3944]. On the other hand, it can enhance the technological level of architectural production, reduce pollution in the construction process, and improve the safety and quality of construction projects. The new industrialization of construction contributes to the reduction of carbon intensity, which is important for promoting the sustainable development of the construction industry.

Climate change continuously threatens the development of human and ecological environments. Control of $\mathrm{CO}_{2}$ emissions in the construction industry 
contributes immeasurably to formulate practical energysaving and emissions-reduction policies. Evaluation of carbon intensity in this sector achieves two purposes: revealing spatial dependence characteristics and regional disparity, and examining the main drivers of carbon intensity, which provide a scientific basis for formulating regional-oriented emissions-reduction policies. In the meantime, the research method used in this study can be applied to other regions or sectors, so as to analyze the spatiotemporal characteristics and impact factors of carbon emissions.

\section{Acknowledgements}

This research is sponsored by the National Social Science Foundation of China (grant No. 16CJY028).

\section{References}

1. HU X., LIU C. Carbon productivity: a case study in the Australian construction industry. Journal of Cleaner Production. 112, 2354, 2016. http://www.sciencedirect.com/ science/article/pii/S0959652615014262

2. WANG S.S., ZHOU D.Q., ZHOU P., WANG Q.W. $\mathrm{CO}_{2}$ emissions, energy consumption and economic growth in China: A panel data analysis. Energy Policy. 39 (9), 4870, 2011. http://www.sciencedirect.com/science/article/pii/ S0301421511004885

3. ZHANG Y., PENG Y., MA C., SHEN B. Can environmental innovation facilitate carbon emissions reduction? Evidence from China. Energy Policy. 100, 18, 2017. http://www. sciencedirect.com/science/article/pii/S0301421516305481

4. YONG G. Eco-indicators: Improve China's sustainability targets. Nature. 477 (7363), 162, 2011. http://www.nature. com/nature/journal/v477/n7363/full/477162b.html

5. AVETISYAN H.G., MILLER-HOOKS E., MELANTA S. Decision models to support greenhouse gas emissions reduction from transportation construction projects. Journal of Construction Engineering \& Management. 138 (5), 631, 2011. https://www.researchgate.net/ publication/275183039_Decision_Models_to_Support_ Greenhouse Gas Emissions Reduction from Transportation_Construction_Projects

6. TRUITT P. Potential for reducing greenhouse gas emissions in construction sector, US Environmental Protection Agency, 2009. http://refhub.elsevier.com/S0360-1323(15)30119-0/ sref12

7. AMANO K., EBIHARA M. Eco-intensity analysis as sustainability indicators related to energy and material flow. Management of Environmental Quality An International Journal. 16 (2), 160, 2005. https://www.researchgate. net/publication/228841568_Eco-intensity_analysis_as_ sustainability indicators related to energy and material flow

8. LAI X., LIU J., GEORGIEV G. Low carbon technology integration innovation assessment index review based on rough set theory - an evidence from construction industry in China. Journal of Cleaner Production. 126, 88, 2016. http://www.sciencedirect.com/science/article/pii/ S0959652616301020

9. CHUAI X., HUANG X., WANG W., WEN J., CHEN Q.,
PENG J. Spatial econometric analysis of carbon emissions from energy consumption in China. Journal of Geographical Sciences. 22 (4), 630, 2012. https://link.springer.com/ article/10.1007/s11442-012-0952-Z

10. LONG R., SHAO T., CHEN H. Spatial econometric analysis of China's province-level industrial carbon productivity and its influencing factors. Applied Energy. 166, 210, 2016. http://www.sciencedirect.com/science/article/pii/ S030626191501226X

11. LI H., MU H., ZHANG M., LI N. Analysis on influence factors of China's $\mathrm{CO}_{2}$ emissions based on Path-STIRPAT model. Energy Policy. 39 (11), 6906, 2011. http://www. sciencedirect.com/science/article/pii/S0301421511006537

12. XU S., HE Z., LONG R. Factors that influence carbon emissions due to energy consumption in China: Decomposition analysis using LMDI. Applied Energy. 127, 182, 2014. http://www.sciencedirect.com/science/article/ pii/S0306261914003833

13. ZHANG Y., DA Y. The decomposition of energy-related carbon emission and its decoupling with economic growth in China. Renewable and Sustainable Energy Reviews. 41, 1255, 2015. http://www.sciencedirect.com/science/article/ pii/S1364032114007941

14. LU Z., YANG Y., WANG J. Factor Decomposition of Carbon Productivity Chang in China's Main Industries: Based on the Laspeyres Decomposition Method. Energy Procedia. 61，1893, 2014. http://www.sciencedirect.com/ science/article/pii/S1876610214032652

15. SHAO C., GUAN Y., WAN Z., GUO C., CHU C., JU $M$. Performance and decomposition analyses of carbon emissions from industrial energy consumption in Tianjin, China. Journal of Cleaner Production. 64, 590, 2014. http://www.sciencedirect.com/science/article/pii/ S0959652613005398

16. GENG Y., ZHAO H., LIU Z., XUE B., FUJITA T., XI F. Exploring driving factors of energy-related $\mathrm{CO}_{2}$ emissions in Chinese provinces: A case of Liaoning. Energy Policy. 60, 820, 2013. http://www.sciencedirect.com/science/ article/pii/S030142151300390X

17. LU S., LU C., TSENG K., CHEN F., CHEN C. Energysaving potential of the industrial sector of Taiwan. Renewable and Sustainable Energy Reviews. 21, 674, 2013. http://www.sciencedirect.com/science/article/pii/ S136403211300052X

18. WANG P., WU W., ZHU B., WEI Y. Examining the impact factors of energy-related $\mathrm{CO}_{2}$ emissions using the STIRPAT model in Guangdong Province, China. Applied Energy. 106, 65 , 2013. http://www.sciencedirect.com/science/article/pii/ S0306261913000457

19. LU Y., CUI P., LI D. Carbon emissions and policies in China's building and construction industry: Evidence from 1994 to 2012. Building and Environment. 95, 94, 2016. http://www. sciencedirect.com/science/article/pii/S0360132315301190

20. FENG B., WANG X. Research on carbon decoupling effect and influence factors of provincial construction industry in China. China Population, Resources and Environment. 4 (25), 28, 2015. http://en.cnki.com.cn/Article en/CJFDTotalZGRZ201504004.htm

21. XU B., LIN B. Reducing carbon dioxide emissions in China's manufacturing industry: a dynamic vector autoregression approach. Journal of Cleaner Production. 131，594, 2016. http://www.sciencedirect.com/science/ article/pii/S0959652616304176

22. SHAO S., LIU J., GENG Y., MIAO Z., YANG Y. Unco-vering driving factors of carbon emissions from China's mining sector. Applied Energy. 166, 220, 
2016. http://www.sciencedirect.com/science/article/pii/ S0306261916300277

23. YAN Q., ZHANG Q., ZOU X. Decomposition analysis of carbon dioxide emissions in China's regional thermal electricity generation, 2000-2020. Energy. 112, 788, 2016. http://www.sciencedirect.com/science/article/pii/ S0360544216309100

24. ANSELIN L. Spatial Econometrics: Methods and Models, Dordrecht: Kluwer Academic Publishers, 17, 1998. https:// link.springer.com/book/10.1007/978-94-015-7799-1

25. LESAGE J.P., PACE R.K. Introduction to Spatial Econometric, Boca Raton: CRC Press, 2009. https://www. researchgate.net/publication/267676434_Introduction_to Spatial_Econometrics_CRC_Press_Boca_Raton_FL

26. BURNETT J.W., BERGSTROM J.C., DORFMAN J.H. A spatial panel data approach to estimating U.S. state-level energy emissions. Energy Economics. 40, 396, 2013. http://www.sciencedirect.com/science/article/pii/ S0140988313001667

27. YANG Y., CAI W., WANG C. Industrial $\mathrm{CO}_{2}$ intensity, indigenous innovation and $\mathrm{R} \& \mathrm{D}$ spillovers in China's provinces. Applied Energy. 131, 117, 2014. http://www. sciencedirect.com/science/article/pii/S0306261914006151

28. ZHAO X., BURNETT J.W., FLETCHER J.J. Spatial analysis of China province-level $\mathrm{CO}_{2}$ emission intensity. Renewable and Sustainable Energy Reviews. 33, 1, 2014. http://www. sciencedirect.com/science/article/pii/S1364032114000793

29. CHENG Y., WANG Z., YE X., WEI Y.D. Spatiotemporal dynamics of carbon intensity from energy consumption in China. Journal of Geographical Sciences. 24 (4), 631, 2014. https://link.springer.com/article/10.1007/s11442-014$1110-6$

30. ZHANG Z., LIU R. Carbon emissions in the construction sector based on input-output analyses. Journal of Tsinghua University (Science and Technology). 53 (1), 53, 2013. http://www.cnki.com.cn/Article/CJFDTOTALQHXB201301010.htm

31. ANSELIN L. Local Indicators of Spatial Association-LISA. Geographical Analysis. 27 (2), 93, 1995. http://onlinelibrary. wiley.com/doi/10.1111/j.1538-4632.1995.tb00338.x/full

32. LALOR G., ZHANG C.S. Multivariate outlier detection and remediation in geochemical databases. Science of The Total Environment. 281, 99, 2001. http://www.sciencedirect.com/ science/article/pii/S0048969701008397

33. ANSELIN L., GRIFFITH D.A. Do spatial effects really matter in regression analysis? Papers in Regional Science. 65, 11, 1988. https://www.researchgate.net/ publication/227681433_Do_spatial_effects_really_matter in_regression_analysis? ${ }^{-} v=$ auth_pub

34. LEGENDRE P. Spatial autocorrelation: trouble or new paradigm? Ecology. 74 (6), 1659, 1993. https:// www.researchgate.net/publication/216812577_Spatial_ Autocorrelation_Trouble_or_New_Paradigm

35. HUANG J., HUANG Y., PONTIUS R.G., ZHANG Z.
Geographically weighted regression to measure spatial variations in correlations between water pollution versus land use in a coastal watershed. Ocean \& Coastal Management. 103, 14, 2015. http://www.sciencedirect.com/ science/article/pii/S0964569114003317

36. SHENG J., HAN X., ZHOU H. Spatially varying patterns of afforestation/reforestation and socio-economic factors in China: a geographically weighted regression approach. Journal of Cleaner Production. 153, 362, 2017. http://www. sciencedirect.com/science/article/pii/S0959652616307326

37. FOTHERINGHAMA.S., CHARLTON M., BRUNSDON C. The geography of parameter space: an investigation of spatial non-stationarity. International Journal of Geographical Information Systems. 10 (5), 605, 1996. http://www. tandfonline.com/doi/abs/10.1080/02693799608902100

38. BOWMAN A.W. An Alternative Method of Crossvalidation for the Smoothing of Density Estimates. Biometrika. 71 (2), 353, 1984. https://www.researchgate. net/publication/224817256_An_Alternative_Method_of_ Cross-Validation for the Smoothing_of Density_Estimate

39. SANTOS R., COSTA A.A., GRILO A. Bibliometric analysis and review of Building Information Modelling literature published between 2005 and 2015. Automation in Construction. 80, 118, 2017. http://www.sciencedirect.com/ science/article/pii/S0926580517302297

40. WONG J.K.W., LI H., WANG H., HUANG T., LUO E., LI V. Toward low-carbon construction processes: the visualisation of predicted emission via virtual prototyping technology. Automation in Construction. 33, 72, 2013. http://www. sciencedirect.com/science/article/pii/S092658051200163X

41. BARATI K., SHEN X. Operational level emissions modelling of on-road construction equipment through field data analysis. Automation in Construction. 72, 338, 2016. http://www.sciencedirect.com/science/article/pii/ S0926580516301649

42. AZZI M., DUC H., HA Q.P. Toward sustainable energy usage in the power generation and construction sectors - a case study of Australia. Automation in Construction. 59, 122, 2015. http://www.sciencedirect.com/science/article/ pii/S0926580515001661

43. WONG J.K.W., ZHOU J. Enhancing environmental sustainability over building life cycles through green BIM: A review. Automation in Construction. 57, 156, 2015. http://www.sciencedirect.com/science/article/pii/ S0926580515001211

44. YEPES V., MARTÍ J.V., GARCÍA-SEGURA T. Cost and $\mathrm{CO}_{2}$ emission optimization of precast - prestressed concrete U-beam road bridges by a hybrid glowworm swarm algorithm. Automation in Construction. 49, 123, 2015. http://www.sciencedirect.com/science/article/pii/ S0926580514002246 